\title{
Influence of Polymeric Coating the Aggregate Surface on Moisture Damage of Hot Mix Asphalt
}

\author{
Mojtaba Khodadadi ${ }^{1}$, Alireza Azarhoosh ${ }^{2 *}$, Ali Khodaii ${ }^{1}$ \\ ${ }^{1}$ Department of Civil \& Environmental Engineering, Amirkabir University of Technology, PO Box: 4413-15875, Tehran, Iran \\ 2 Department of Civil Engineering, University of Bojnord, Bojnord, PO Box: 9453155111, North Khorasan, Iran \\ * Corresponding author, e-mail: azarhoosh@ub.ac.ir
}

Received: 08 May 2019, Accepted: 14 November 2020, Published online: 30 November 2020

\begin{abstract}
Moisture damage is one of the common causes of asphalt pavement failure in moisture presence. One of the convenient approaches to decreasing moisture sensitivity in hot-mix asphalt is coating the aggregate surface with a suitable agent. In this study, the effects of polyethylene terephthalate on moisture damage of asphalt mixtures were evaluated by applying indirect tensile strength and resilient modulus tests. The asphalt specimens were prepared with two types of aggregates (granite and limestone) and neat asphalt binder of 60/70 penetration grade. The results showed that the ratio of wet/dry values of indirect tensile strength and resilient modulus for mixtures containing limestone was higher than those of the samples with granite aggregate. Furthermore, the results of the laboratory tests indicate that polyethylene terephthalate improves resistance to moisture susceptibility. Because polyethylene terephthalate increases the wettability of asphalt binder over the aggregate and the adhesion between the asphalt binder and aggregate, especially in the mixtures containing acidic (granite) aggregate prone to moisture damage.
\end{abstract}

Keywords

hot mix asphalt, moisture damage, polyethylene terephthalate, indirect tensile strength, resilient modulus

\section{Introduction}

Construction and rehabilitation of road pavements is a major concern all over the world due to limited resources. The empirical design was gradually replaced by the mechanistic-empirical models due to limitations in the selection of design inputs. A variety of mechanistic-empirical models have been used in the last decade to consider, in addition to the impact of traffic load, the analysis of environmental impacts on design inputs $[1,2]$. One of the environmental parameters affecting the pavement performance is moisture, which causes moisture damage in it.

The presence of water in road pavement layers is evident for unbound granular layers such as subgrades and subbase layers; however, its presence in and between bound layers, especially asphalt layers, is still considered a novelty to the wider professional community, despite numerous publications have been available in this field since the 1960s [3]. Invasion of moisture into the asphalt layers reduces its strength and promote distresses (for example stripping, raveling, fatigue damage, and/or permanent deformation). Two types of factor can increase the moisture susceptibility of the asphalt mixture: internal and external factors. The internal factors are related to the properties of the materials and the microstructure distribution, while the external factors include the environmental conditions, production and construction practices, pavement design, and traffic level [4].

Additives have been used for improving the performance of HMA pavements to various distresses. The use of the anti-stripping agent is the most common method to improve the moisture susceptibility of asphalt mixtures [5]. In order to improve adhesion and reduce moisture sensitivity in asphalt mixtures, two general categories of anti-stripping agents become apparent. The first category suggests the aggregate surface to be coated by a suitable agent that will reverse the predominant electrical charges at the surface and thus reduce the surface energy of the aggregate. The second approach is to reduce the surface energy of the binder with suitable agents and give an electrical charge opposite to that of the aggregate surface [6]. 


\subsection{Literature review}

Of the many ways to prevent moisture damage in pavements, the use of anti-stripping additives is deemed the most effective. Wasiuddin et al. [7] evaluated the moisture sensitivity of two types of HMA mixtures made with two types of aggregate with and without styrene-butadiene- rubber (SBR) treatment for moisture-induced damage potential. SBR coating altered the aggregate surface from hydrophilic to hydrophobic and thereby increased the wettability of the asphalt binder over the aggregate. Tohme et al. [8] examined the resilient modulus and tensile strength properties of the field mixed-laboratory compacted samples measured at both unconditioned and conditioned stages, and showed that the mixtures treated with hydrated lime on both projects (SD-314 and US-14) exhibited better moisture resistance the control and mixtures containing liquid anti-stripping agents. The superior performance of the mixtures treated with hydrated lime was shown by higher retained strength after the moisture conditioning process.

Sohrabi et al. [9] studied the effect of modifying aggregate surface by micronized calcium carbonate on increasing the moisture resistance of asphalt mixtures. The results obtained by mechanical methods show that modification of aggregates surface causes an increase in the tensile strength ratio (TSR) in the samples made by both two types of asphalt binder. In addition, results of surface free energy method indicate the increase of adhesion energy (except in granite samples) and reduction of de-bonding energy in all modified samples. Generally, evaluations conducted by the use of both methods show that covering aggregates by micronized calcium carbonate has a positive effect on reducing moisture sensitivity of asphalt mixes.

In another study, the hydrophobic coating on aggregate surfaces was used to reduce moisture damage in asphalt mixture. The results obtained in the study indicate that the hydrophobic coating on the surface of the aggregate has caused the acidic and basic components of surface free energy to reduce and increase, respectively. The changes have caused an increase in the adhesion of the asphalt binder aggregate and the better wettability of asphalt binder over the aggregate. Finally, the treatment of aggregate surface with hydrophobic agent reduced the difference between the free energy of adhesion of aggregate-asphalt binder in dry and wet conditions, decreasing the rate of moisture damage [10]. Also, Akbari and Modares [11] have investigated the effect of utilizing Nano clay (NC) and Nano Limestone (NL) on asphalt mixtures durability during freeze-thaw cycles. The result of this study revealed that the addition of NC and NL increased the indirect tensile strength and resilient modulus of HMA. Therefore, moisture susceptibility potential of modified HMA was decreased.

\subsection{Statement and objectives of the present study}

The most imperative purpose of this investigation is to increase the resistance of asphalt mixtures against moisture damage. In order to accomplish that, the materials of asphalt mixtures are modified in order to increase the resistance of mixtures. According to the literature review, it can be seen that the most effective way to create asphalt mixtures resistant to moisture damage is using anti-stripping materials. Many additives are studied to be feasible in asphalt mixtures, some key factors like making asphalt mixtures resistant to moisture (the most important purpose of this study), non-existent issues in other technical specifications of the mixture, performance considerations, economic considerations and environmental considerations are found to be most significant parameters for designers.

In this study to reduce moisture susceptibility is the use of a coating aggregate treatment system providing a protective barrier on the aggregate, which repels water and waterproofs the aggregate while providing an improved bonding with the asphalt binder. Hence, the effect of Freeze-thaw cycles on moisture damage in modified HMA with PET using indirect tensile strength (ITS) and resilient modulus $(\mathrm{Mr})$ tests are investigated.

The specific objectives of this study are to:

- Evaluate the effect of PET as an anti-stripping agent on the moisture damage of HMA,

- Evaluating the behavior of HMA mixtures under ITS and $M r$ tests in dry and wet conditions with and without PET treated aggregates,

- Selection of aggregate, asphalt binder and anti-stripping additive systems which are more resistant to the moisture damage.

\section{Materials}

\subsection{Aggregate and asphalt binder}

Granite and limestone aggregates with relatively high and low moisture susceptibility were used to study the effect of PET. The chemical composition of the aggregates were obtained using X-ray fluorescence (XRF) test and presented in Table 1. The physical properties of the two types of aggregates are given in Table 2. Aggregates gradation was selected according to ASTM D3515-01 [12] as shown in Fig. 1. 
Table 1 Chemical composition of the two types of aggregates

\begin{tabular}{lcc}
\hline Properties & Limestone & Granite \\
\hline Silicon dioxide, $\mathrm{SiO}_{2}(\%)$ & 4.5 & 78.1 \\
Aluminum oxide, $\mathrm{Al}_{2} \mathrm{O}_{3}(\%)$ & 3.2 & 12.3 \\
Ferric oxide, $\mathrm{Fe}_{2} \mathrm{O} 3(\%)$ & 1.1 & 2.5 \\
Magnesium oxide, $\mathrm{MgO}(\%)$ & 5.6 & 0.6 \\
Calcium oxide, $\mathrm{CaO}(\%)$ & 73.4 & 2.1 \\
\hline
\end{tabular}

Table 2 Physical properties of the two types of aggregates

\begin{tabular}{|c|c|c|c|c|}
\hline Test & Standard & Limestone & Granite & $\begin{array}{c}\text { Specification } \\
\text { limit }\end{array}$ \\
\hline $\begin{array}{l}\text { Specific gravity } \\
\text { (coarse agg.) }\end{array}$ & $\begin{array}{c}\text { ASTM C } 127 \\
{[13]}\end{array}$ & & & \\
\hline Bulk & & 2.715 & 2.755 & - \\
\hline SSD & & 2.732 & 2.763 & - \\
\hline Apparent & & 2.761 & 2.789 & - \\
\hline $\begin{array}{l}\text { Specific gravity } \\
\text { (fine agg.) }\end{array}$ & $\begin{array}{c}\text { ASTM C } 128 \\
{[14]}\end{array}$ & & & \\
\hline Bulk & & 2.722 & 2.761 & - \\
\hline SSD & & 2.739 & 2.768 & - \\
\hline Apparent & & 2.753 & 2.782 & - \\
\hline $\begin{array}{l}\text { Specific } \\
\text { gravity (filler) }\end{array}$ & $\begin{array}{c}\text { ASTM D854 } \\
{[15]}\end{array}$ & 2.740 & 2.759 & - \\
\hline $\begin{array}{l}\text { Los Angeles } \\
\text { abrasion (\%) }\end{array}$ & $\begin{array}{c}\text { ASTM C } 131 \\
{[16]}\end{array}$ & 32 & 25 & $\operatorname{Max} 45$ \\
\hline $\begin{array}{l}\text { Flat and } \\
\text { elongated } \\
\text { particles }(\%)\end{array}$ & $\begin{array}{c}\text { ASTM D } 4791 \\
{[17]}\end{array}$ & 4.1 & 6.7 & $\operatorname{Max} 10$ \\
\hline $\begin{array}{l}\text { Sodium sulfate } \\
\text { soundness }(\%)\end{array}$ & $\begin{array}{c}\text { ASTM C } 88 \\
{[18]}\end{array}$ & 3.32 & 2.1 & Max 10-20 \\
\hline $\begin{array}{l}\text { Fine aggregate } \\
\text { angularity }\end{array}$ & $\begin{array}{c}\text { ASTM C } 1252 \\
{[19]}\end{array}$ & 47.21 & 59.15 & $\operatorname{Min} 40$ \\
\hline
\end{tabular}

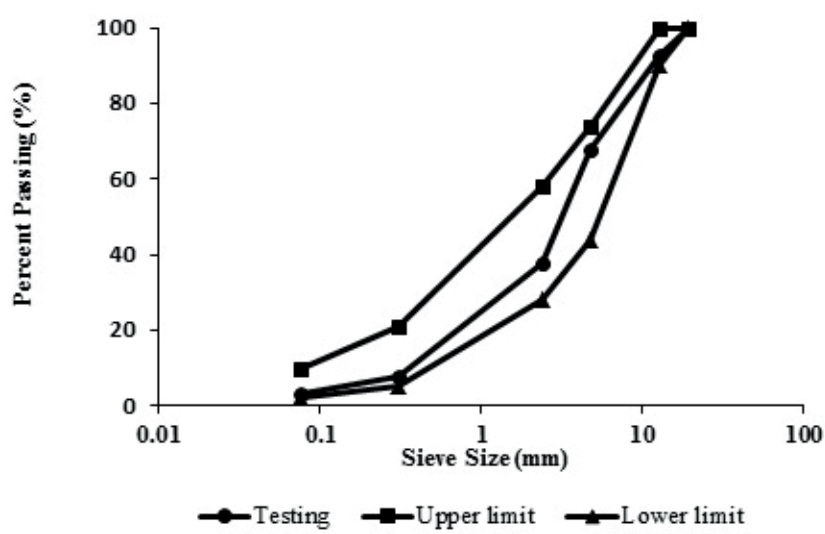

Fig. 1 Aggregate gradation used in this study

The asphalt binder with a $60 / 70$ penetration grade (PG 58-16) was utilized. The conventional test was performed to derive asphalt binder properties, and results are presented in Table 3.

\subsection{Additives}

Polyethylene terephthalate (PET) is a general-purpose thermoplastic polymer which belongs to the polyester family of polymers. Polyester resins are known for their excellent combination of properties such as mechanical, thermal, chemical resistance as well as dimensional stability. The PET is highly flexible and semi-crystalline resin in its natural state. Depending upon how it is processed, it can be semi-rigid to rigid. It shows good dimensional stability, resistance to impact, moisture, alcohols and solvents [26]. The molecular structure of PET is shown in Fig. 2. Also, the properties of PET are given in Table 4.

\section{Experimental setup and procedure}

Flowchart of experimental design of this study is presented in Fig. 3. Furthermore, three HMA samples were prepared for each test condition and combination of asphalt binder and aggregate to determine the reproducibility of the results.

\subsection{Aggregate coating}

In the PET coating method, the PET with 2, 4, 6, 8 and $10 \%$ by coarse aggregate weight is added and mixed with aggregate. The sufficient temperature of the created mixture for

Table 3 Results of the experiments conducted on asphalt binder used in

\begin{tabular}{lcc}
\multicolumn{3}{c}{ this study } \\
\hline Test & Standard & Result \\
\hline Penetration $\left(100 \mathrm{~g}, 5 \mathrm{~s}, 25^{\circ} \mathrm{C}\right), 0.1 \mathrm{~mm}$ & ASTM D5 [20] & 66.8 \\
Penetration $\left(200 \mathrm{~g}, 60 \mathrm{~s}, 4{ }^{\circ} \mathrm{C}\right), 0.1 \mathrm{~mm}$ & ASTM D5 [20] & 25 \\
Penetration ratio & ASTM D5 [20] & 0.36 \\
Ductility $\left(25^{\circ} \mathrm{C}, 5 \mathrm{~cm} / \mathrm{min}\right), \mathrm{cm}$ & ASTM D113 [21] & 112 \\
Solubility in trichloroethylene, $\%$ & ASTM D2042 [22] & 98.9 \\
Softening point, ${ }^{\circ} \mathrm{C}$ & ASTM D36 [23] & 47.1 \\
Flash point, ${ }^{\circ} \mathrm{C}$ & ASTM D92 [24] & 273 \\
Loss of heating, $\%$ & ASTM D1754 [25] & 0.72 \\
\hline
\end{tabular}

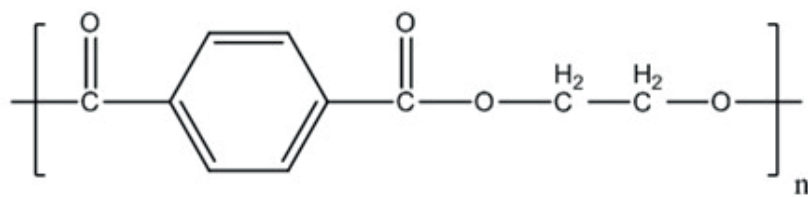

Fig. 2 Molecular Structure of Polyethylene Terephthalate (C10H8O4)n

Table 4 Properties of PET was used in this study

\begin{tabular}{lcc}
\hline Test & Standard & PET \\
\hline Density $\left(\mathrm{g} / \mathrm{cm}^{3}\right)$ & ASTM-D792 [27] & 0.95 \\
Water Absorption, 24 hours (\%) & ASTM-D570 [28] & 0 \\
Tensile Strength (MPa) & ASTM-D638 [29] & 21.5 \\
Tensile Elongation at Yield (\%) & ASTM-D638 [29] & $770-800$ \\
\hline
\end{tabular}




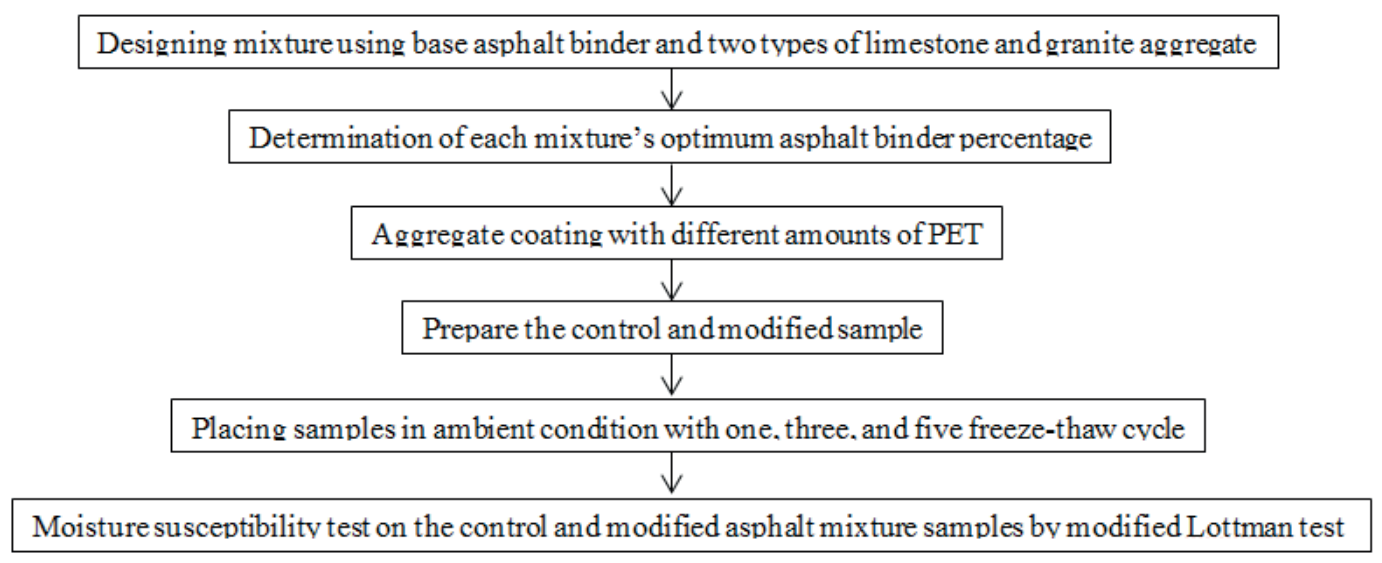

Fig. 3 Flow chart of experimental design of this study

the melting of PET and spreading it over the aggregate surface is $240-250{ }^{\circ} \mathrm{C}$. To avoid aggregate lumping, the produced mixture is mixed slowly for 5 minutes. The steps for preparing aggregates are shown in Fig. 4.

\subsection{Mix design methodology}

Asphalt mixtures were designed by Marshall mix design method according to ASTM D6927 - 15 [30]. Two series of Marshall specimens were produced. The first series that contained different amounts of asphalt binder was used for determining the optimum asphalt binder and the second series was used with the optimum asphalt binder for evaluating moisture damage of the asphalt mixtures.

The optimum asphalt binder content for the asphalt mixtures was obtained from the average of three different amounts of asphalt binder in order to meet the following conditions:

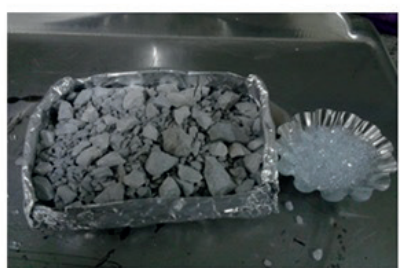

(a)

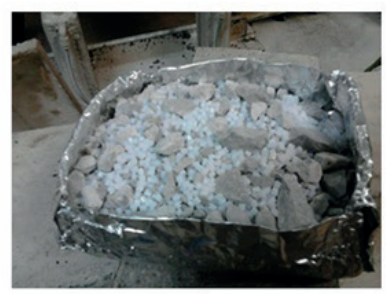

(c)

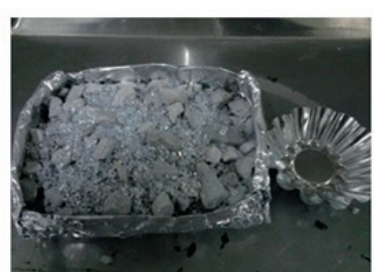

(b)

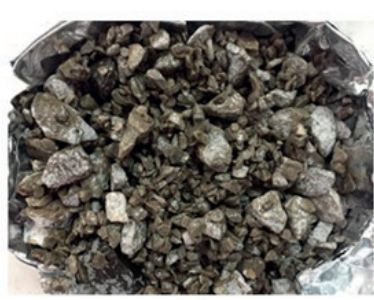

(d)
Fig. 4 Steps of aggregate surface coatings: (a) aggregate \& PET (b) initial mixing (c) Initial heating (d) final coating
1 Asphalt binder content corresponding to maximum stability;

2 Asphalt binder content corresponding to maximum bulk specific gravity; and

3 Asphalt binder content corresponding to $4 \%$ air voids in the total mix.

The flow value, voids mineral aggregate (VMA) and voids filled with bitumen (VFB) are checked with the Marshall mix design specification. Therefore, due to the above issues, the optimum asphalt binder content for mixtures containing granite and limestone were obtained as $5.1 \%$ and $5.5 \%$, respectively.

\subsection{Moisture susceptibility determination of HMA} Indirect tensile strength test (AASHTO T283) [31] and resilient modulus (ASTM D7369) [32] determine the HMA moisture damage in a certain temperature and damage mechanism based on the mechanical loading applied to three different freeze-thaw cycles (1,3 and 5) on asphalt mixture samples.

The wet samples are first saturated with relative vacuum conditions (absolute pressure of 13-67 kPa) for five minutes. Then they are kept in a submerged state and without vacuum conditions for 5-10 minutes. The samples are then taken out and their mass is measured and percentage of saturation of the samples is obtained. If the saturation percentage is less than $70 \%$, the samples should be placed under vacuum conditions again. If sample saturation is more than $80 \%$, the sample is considered to be damaged and a new sample should be made instead. Lower vacuum times must be considered for the new samples so that their saturation to be between 70 and $80 \%$. Saturated samples are placed inside plastic bags and 10 
$\mathrm{ml}$ of water are poured inside the bags. The samples are stored inside the freezer at $-18{ }^{\circ} \mathrm{C}$ for 16 hours. Then, the samples were taken to a hot water bath at $60{ }^{\circ} \mathrm{C}$. They are then taken out of plastic bags and allowed to remain at this temperature for 24 hours. At the end, the samples are brought to room temperature $\left(25^{\circ} \mathrm{C}\right)$; in this way, they are called wet samples [31].

The tensile strength ratio (TSR) index which is calculated from Eq. (1) can be used to determine the moisture damage potential of HMA. It is believed that the higher value of this ratio corresponds to higher resistance against moisture damage [31].

$T S R=\left(\frac{I T S_{w e t}}{I T S_{d r y}}\right) \times 100$,

in which, ITS $S_{\text {wet }}$ is the average ITS value of the wet set samples that are subjected to freeze-thaw cycles, and ITS $S_{d r y}$ is the average ITS value of the dry set samples.

Also the resilient modulus ratio (RMR) can be determined from Eq. (2), as an indicator of the HMA moisture susceptibility [32]:

$R M R=\left(\frac{M r_{w e t}}{M r_{d r y}}\right) \times 100$,

where $M r_{\text {wet }}$ is the average $M r$ value of the wet set samples, and $M r_{d r y}$ is the average $M r$ of the dry set samples.

Although it has remained a challenge for researchers to present a practical test procedure to determine moisture damage of asphalt mixture, these mentioned tests (ITS and Mr) has been accepted and widely used [33].

\section{Results and discussion}

\subsection{Indirect tensile strength test}

The ITS values of asphalt mixtures are determined according to AASHTO T283 standard test, and results are presented in Figs. 5 and 6 . As shown in these figures, the ITS values for each dry and wet sample of a mix with and without PET under dry and wet conditions are compared. Considering these figures, the ITS decreased by increasing freeze-thaw cycles. This was expected because the presence of water causes a reduction in asphalt-aggregate adhesion, and thus the strength of asphalt mixture samples decrease under loading. As mixtures containing modified limestone with 2, 4, 6, 8, and $10 \%$ PET have 1.07, 1.13, $1.44,1.28$, and 1.21 times more tensile resistance than control mixtures at 5 freeze-thaw cycles, respectively. These values for mixtures with granite aggregate are 1.1, 1.19, $1.51,1.32$, and $1.26 \%$, respectively.

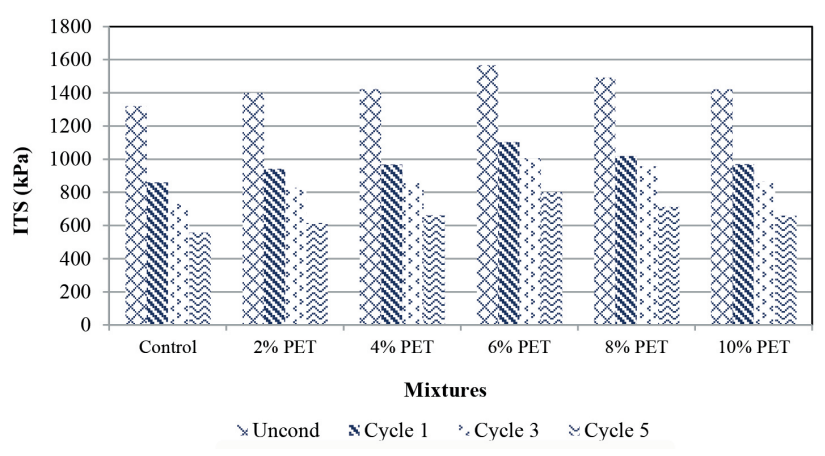

Fig. 5 Unconditioned and conditioned ITS values in samples containing granite aggregate

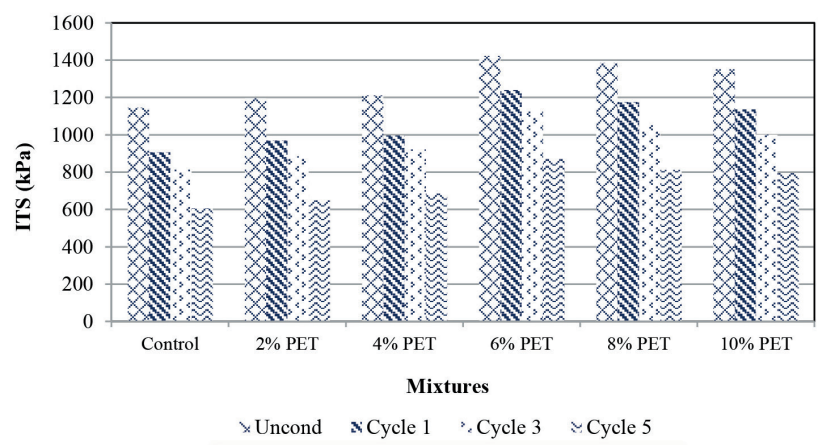

Fig. 6 Unconditioned and conditioned ITS values in samples containing limestone aggregate

This result was obtained in the previous research as well $[34,35]$. In addition, it is observed that the use of PET additive to $10 \%$ led to the improvement of the strength of modified asphalt mixtures compared to control samples. The main reason of this change is that in aggregate modified with PET, aggregate- asphalt binder adhesion will be increased. Also, as can be seen, the $6 \%$ PET is optimal content for both aggregates (limestone and granite). Because the use of more PET ( $8 \%$ and $10 \%$ in this study) reduces the workability and therefore the mixing and compaction of asphalt samples will be difficult.

Figs. 7 and 8 showed the unconditioned and moisture conditioned TSR properties of the HMA for two types of aggregates. The TSR of the control mixtures (without PET) containing limestone is greater than those of control mixtures containing granite, which leads to better resistance against moisture damage. Since granite has more $\mathrm{SiO} 2$ compared to limestone, this causes a reduction in the bond between asphalt and aggregate in the presence of water. The data also shows that the TSR values are significantly improved with the addition of PET for both aggregates. Most aggregates have electrically charged surfaces (polar surfaces). Asphalt binder, which is composed chiefly of high molecular weight hydrocarbons, exhibits little polar activity; therefore, the bond that develops between asphalt 


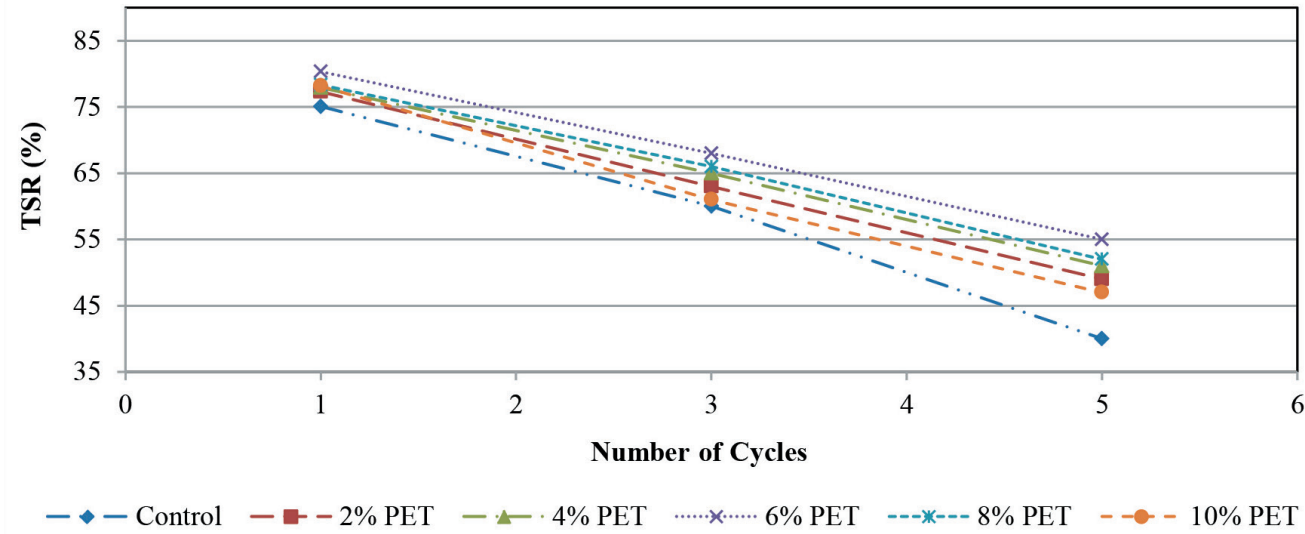

Fig. 7 Effect of PET and Freeze-Thaw Cycles on TSR of Mixtures containing granite aggregate

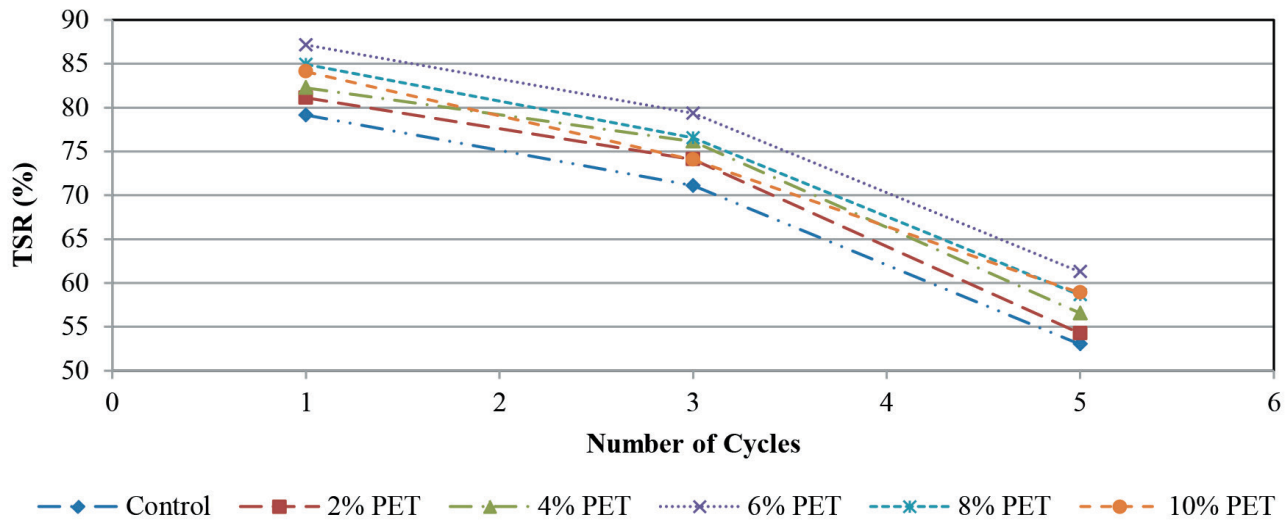

Fig. 8 Effect of PET and Freeze-Thaw Cycles on TSR of Mixtures containing limestone aggregate

and an aggregate is primarily due to relatively weak dispersion forces. PET treatment alters the aggregate surface by increasing its non-polarity for increased wettability of asphalt on the aggregate. All of the TSR values of the PETtreated mixtures are well above $77 \%$ for 1 freeze-thaw cycle. Also, the samples made by limestone and $6 \%$ PET have the highest amount of the indirect tensile strength ratio $(87 \%)$ in the first cycle and this amount is reduced to $61 \%$ at the fifth cycle.

As depicted in Figs. 7 and 8, the use of PET had a lower impact on the strength of asphalt mixtures made with limestone aggregate. This can be due to the proper asphalt binder -aggregate adhesion in the base state, as the limestone aggregates create a suitable adhesion with asphalt binder, which is an acidic matter. The use of PET also enhances the strength of specimens containing this aggregate to the same amount in both dry and wet conditions. This leads to a slight improvement in the index of the indirect tensile strength to moisture in specimens made with this kind of aggregate. However, in contrast, regarding specimens made with granite acidic aggregates, the use of PET has remarkably improved the performance of the asphalt mixture against moisture.

\subsection{Resilient modulus test}

ASTM D7369 [32] standard test was conducted to determine Mr values and the results are shown in Figs. 9 and 10. In this method similar to ITS test, HMA samples are subjected to various freeze-thaw cycles. Resilient modulus is an engineering property that describes the stress-strain relationship of the HMA mix. A reduction in the resilient modulus property after freeze-thaw cycling leads to an increase in the strain experienced by the HMA mixture due to traffic induced stresses. As the HMA is subjected to higher strain, its tendency to experience rutting and fatigue cracking would increase [36].

The results show that mixtures with PET have a higher resilient modulus than those of the control mixture in wet conditions. This means that the use of PET causes an increase in the strength of the mixtures against moisture. The higher wet resilient modulus of PET mixtures could be related to the fact that inclusion of PET increases the strength of the mixture due to interlocking phenomenon thus making the mixture more resistant to moisture damage. Interlocking strength has been increased due to penetration of melted PET into the voids of aggregates. That part of PET which has penetrated to the surface voids 
of aggregates constructs a continuous combination with that part of PET located in the space between an aggregate and other aggregates. Hence, interlocking strength between aggregate and asphalt binder increases. Such a continuous combination is connected with the surface of aggregate on one side and with the asphalt binder on

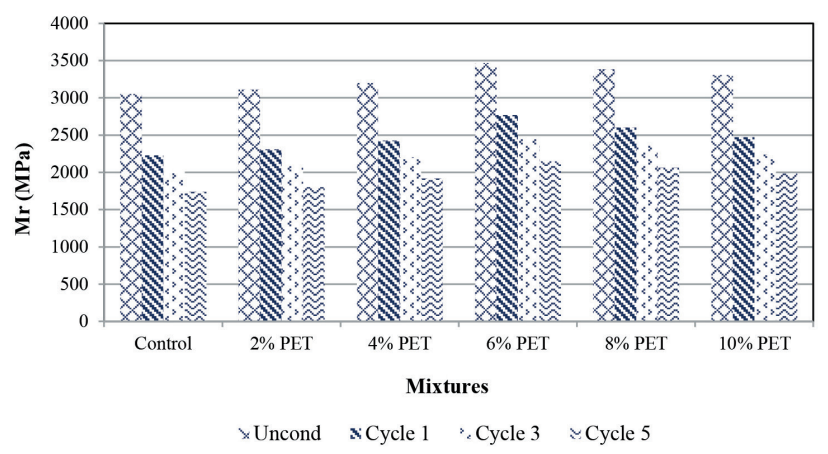

Fig. 9 Unconditioned and conditioned resilient modulus values of samples containing granite aggregate the other side. The usage of the aggregate coating does not have notable change in the resilient modulus of the unconditioned samples.

Figs. 11 and 12 show the ratio of wet/dry resilient modulus for the HMA mixtures treated with different values of PET coating. The data of this figure shows that for the two

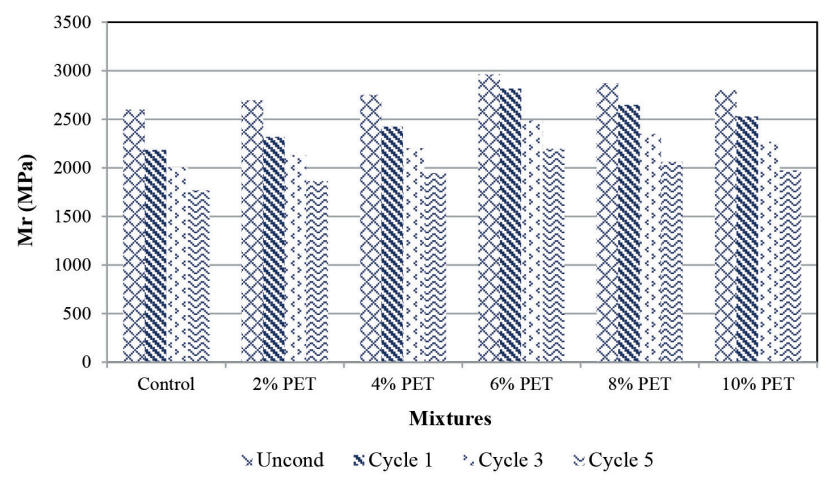

Fig. 10 Unconditioned and conditioned resilient modulus values of samples containing limestone aggregate

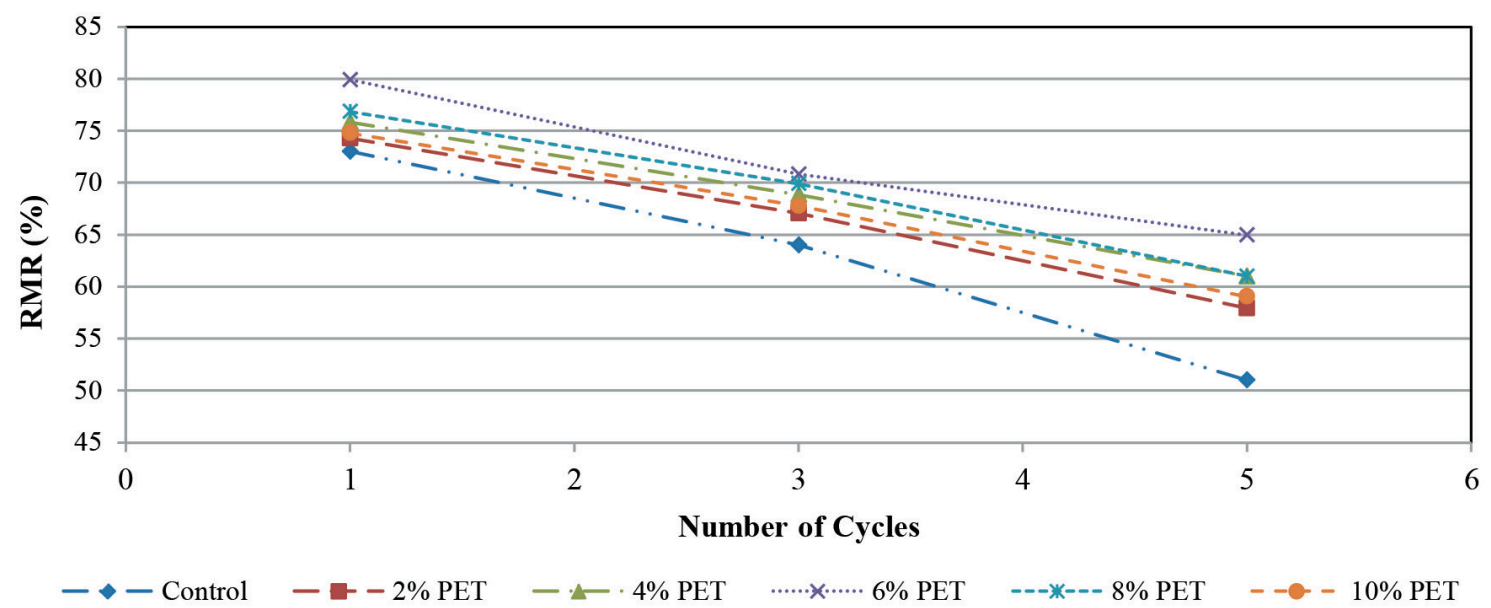

Fig. 11 Effect of PET and Freeze-Thaw Cycles on RMR of Mixtures containing granite aggregate

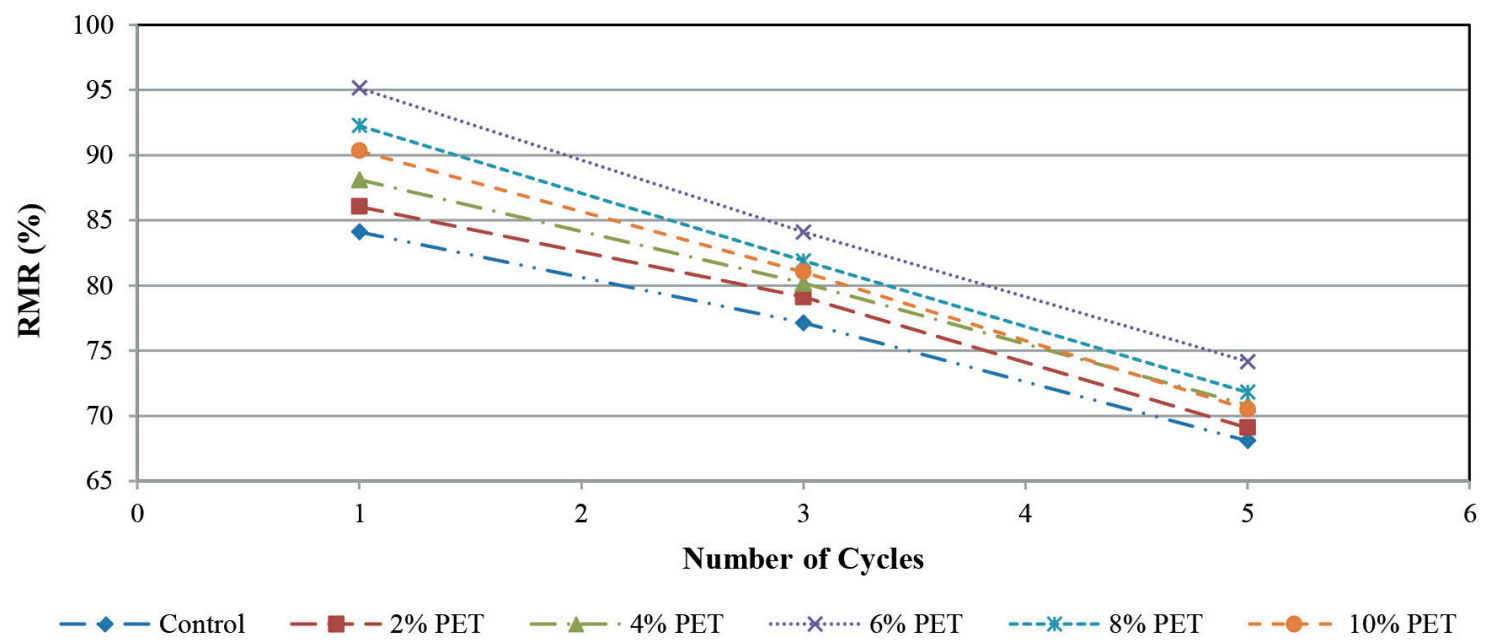

Fig. 12 Effect of PET and Freeze-Thaw Cycles on RMR of Mixtures containing limestone aggregate 
types of aggregate, the use of PET coating has a significant increase in the RMR. This increase in RMR is higher in the samples containing granite aggregate that are prone to moisture damage. In the samples containing limestone aggregate, the use of PET has less improvement in RMR in comparison to the samples containing granite aggregate.

On the other hand, the results show that when the number of freeze-thaw cycles increases the reduction in RMR percentage of modified mix is smaller than control samples. For instance, applying 5 cycles to samples containing granite aggregate and 2, 4, 6, 8 and $10 \%$ of PET causes a decrease of $22.1 \%, 19.5 \%, 18.8 \%, 20.6 \%$ and $21.1 \%$ in RMR, respectively. While the RMR reduction percentage of control samples is $30.1 \%$. This indicates that under various freeze-thaw cycles, the modified samples have higher moisture resistance compared to the unmodified samples.

\section{Conclusions}

This research was conducted with the aim to evaluate the effect of using PET to cover and modify aggregates surface on the reduction of moisture damage of asphalt

\section{References}

[1] Li, Q., Xiao, D. X., Wang, K. C. P., Hall, K. D., Qiu, Y. "Mechanisticempirical pavement design guide (MEPDG): a bird's-eye view", Journal of Modern Transportation, 19(2), pp. 114-133, 2011. https://doi.org/10.1007/BF03325749

[2] Tóth, C., Primusz, P. "New Hungarian mechanistic-empirical design procedure for asphalt pavements", Baltic Journal of Road and Bridge Engineering, 15(1), pp. 161-186, 2020.

https://doi.org/10.7250/bjrbe.2020-15.466

[3] Tóth, C., Soós, Z., Igazvölgyi, Z. "Testing and interpreting permeability of asphalt mixes", Građevinar, 72(5), pp. 395-400, 2020. https://doi.org/10.14256/JCE.2532.2018

[4] Mercado, E. A. "Influence of fundamental material properties and air void structure on moisture damage of asphalt mixes", [pdf] PhD Dissertation, Texas A\&M University, 2007. Available at: https://oaktrust.library.tamu.edu/bitstream/handle/1969.1/ETDTAMU-1276/ARAMBULA-MERCADO-DISSERTATION. pdf? sequence $=1$

[5] Kok, B.V., Yilmaz, M. "The effects of using lime and styrene--butadiene-styrene on moisture sensitivity resistance of hot mix asphalt", Construction and Building Materials, 23(5), pp. 1999-2006, 2009. https://doi.org/10.1016/j.conbuildmat.2008.08.019

[6] Aksoy, A., Şamlioglu, K., Tayfur, S., Özen, H. "Effects of various additives on the moisture damage sensitivity of asphalt mixtures", Construction and Building Materials, 19(1), pp. 11-18, 2005. https://oi.org/10.1016/j.conbuildmat.2004.05.003 mixes. Accordingly, the indirect tensile strength and resilient modulus tests in various cycles of freeze-thaw were used to evaluate moisture resistance of HMA. The most important results obtained by the above tests are presented in the following section:

- Asphalt mixtures prepared with PET have less moisture damage potential compared to the control mixtures. This was true for specimens of both types of aggregates.

- PET treatment of the aggregate increases the ITS and $\mathrm{Mr}$ values in wet condition, which shows that PET treatment of the aggregate reduced the moisture sensitivity of the mixtures.

- The mixtures prepared with limestone aggregates and PET treatment indicates the highest values of TSR and RMR for wet/dry condition. This means that the moisture sensitivity of these mixtures is reduced.

- The PET coating changes the surface of hydrophobic aggregates to hydrophilic and thus, aggregates repel the water. PET fills the small voids of aggregates and acts such as a buffer between aggregate surface and asphalt binder.

[7] Wasiuddin, N. M., Zaman, M. M., O'Rear, E. A. "Polymeric aggregate treatment using styrene-butadiene rubber (SBR) for moisture-induced damage potential", [pdf] International Journal of Pavement Research and Technology, 3(1), pp. 1-9, 2010. Available at: http://www.ijprt.org.tw/reader/pdf.php?id=82

[8] Tohme, P., Sebaali, P. E., Hajj, E. Y., Johnston, D. "Effectiveness of antistrip additives for bituminous mixtures", International Journal of Pavements, 3(2), pp. 50-62, 2004.

[9] Sohrabi, M., Shirmohammadi, H., Hamedi, G. H. "Investigating the Effect of Modifying Aggregate Surface by Micronized Calcium Carbonate on Increasing the Moisture Resistance of Asphalt Mixtures", Periodica Polytechnica Civil Engineering, 63(1), pp. 63-76, 2019.

https://doi.org/10.3311/PPci.11632

[10] Moghadas Nejad, F., Asadi, M., Hamedi, G. H., Esmaeeli, M. R. "Using Hydrophobic Coating on Aggregate Surfaces to Reduce Moisture Damage in Asphalt Mixture", Journal of Materials in Civil Engineering, 30(10), Article number: 04018238, 2018. https://doi.org/10.1061/(ASCE)MT.1943-5533.0002413

[11] Akbari, A., Modarres, A. "Effect of clay and lime nano-additives on the freeze-thaw durability of hot mix asphalt", Road Materials and Pavement Design, 18(3), pp. 646-669, 2017. https://doi.org/10.1080/14680629.2016.1182939

[12] ASTM "ASTM D3515-01 Standard Specification for Hot-Mixed, Hot-Laid Bituminous Paving Mixtures (Withdrawn 2009)", ASTM International, West Conshohocken, PA, USA, 2001. https://doi.org/10.1520/D3515-01 
[13] ASTM "ASTM C127 - 15 Standard Test Method for Relative Density (Specific Gravity) and Absorption of Coarse Aggregate", ASTM International, West Conshohocken, PA, USA, 2015. https://doi.org/10.1520/C0127-15

[14] ASTM "ASTM C128 - 15 Standard Test Method for Relative Density (Specific Gravity) and Absorption of Fine Aggregate", ASTM International, West Conshohocken, PA, USA, 2015. https://doi.org/10.1520/C0128-15

[15] ASTM "ASTM D854 - 14 Standard Test Methods for Specific Gravity of Soil Solids by Water Pycnometer", ASTM International, West Conshohocken, PA, USA, 2014

https://doi.org/10.1520/D0854-14

[16] ASTM "ASTM C131 - 01 Standard Test Method for Resistance to Degradation of Small-Size Coarse Aggregate by Abrasion and Impact in the Los Angeles Machine", ASTM International, West Conshohocken, PA, USA, 2001. https://doi.org/10.1520/C0131-01

[17] ASTM "ASTM D4791 - 19 Standard Test Method for Flat Particles, Elongated Particles, or Flat and Elongated Particles in Coarse Aggregate", ASTM International, West Conshohocken, PA, USA, 2019. https://doi.org/10.1520/D4791-19

[18] ASTM "ASTM C88 - 13 Standard Test Method for Soundness of Aggregates by Use of Sodium Sulfate or Magnesium Sulfate", ASTM International, West Conshohocken, PA, USA, 2013. https://doi.org/10.1520/C0088-13

[19] ASTM "ASTM C1252 - 17 Standard Test Methods for Uncompacted Void Content of Fine Aggregate (as Influenced by Particle Shape, Surface Texture, and Grading)", ASTM International, West Conshohocken, PA, USA, 2017. https://doi.org/10.1520/C1252-17

[20] ASTM "ASTM D5 - 05 Standard Test Method for Penetration of Bituminous Materials", ASTM International, West Conshohocken, PA, USA, 2005. https://doi.org/10.1520/D0005-05

[21] ASTM "ASTM D113 - 17 Standard Test Method for Ductility of Asphalt Materials", ASTM International, West Conshohocken, PA, USA, 2017. https://doi.org/10.1520/D0113-17

[22] ASTM "ASTM D2042 - 15 Standard Test Method for Solubility of Asphalt Materials in Trichloroethylene", ASTM International, West Conshohocken, PA, USA, 2015. https://doi.org/10.1520/D2042-15

[23] ASTM "ASTM D36 - 06 Standard Test Method for Softening Point of Bitumen (Ring-and-Ball Apparatus)", ASTM International, West Conshohocken, PA, USA, 2006. https://doi.org/10.1520/D0036-06

[24] ASTM "ASTM D92 - 18 Standard Test Method for Flash and Fire Points by Cleveland Open Cup Tester", ASTM International, West Conshohocken, PA, USA, 2018. https://doi.org/10.1520/D0092-18

[25] ASTM "ASTM D1754 - 97(2002) Standard Test Method for Effect of Heat and Air on Asphaltic Materials (Thin-Film Oven Test)", ASTM International, West Conshohocken, PA, USA, 1997. https://doi.org/10.1520/D1754-97R02
[26] Ravindranath, K., Mashelkar, R. A. "Polyethylene terephthalate - I. Chemistry, thermodynamics and transport properties", Chemical Engineering Science, 41(9), pp. 2197-2214, 1986. https://doi.org/10.1016/0009-2509(86)85070-9

[27] ASTM "ASTM D792 - 20 Standard Test Methods for Density and Specific Gravity (Relative Density) of Plastics by Displacement", ASTM International, West Conshohocken, PA, USA, 2020. https://doi.org/10.1520/D0792-20

[28] ASTM "ASTM D570 - 98 Standard Test Method for Water Absorption of Plastics", ASTM International, West Conshohocken, PA, USA, 1998. https://doi.org/10.1520/D0570-98

[29] ASTM "ASTM D638 - 14 Standard Test Method for Tensile Properties of Plastics", ASTM International, West Conshohocken, PA, USA, 2014. https://doi.org/10.1520/D0638-14

[30] ASTM "ASTM D6927-15 Standard Test Method for Marshall Stability and Flow of Asphalt Mixtures", ASTM International, West Conshohocken, PA, USA, 2015. https://doi.org/10.1520/D6927-15

[31] Azari, H. "Precision Estimates of AASHTO T283: Resistance of Compacted Hot Mix Asphalt (HMA) to Moisture-Induced Damage", National Academies of Sciences, Engineering, and Medicine, Washington, DC, USA, Rep. NCHRP 166, 2010. https://doi.org/10.17226/22918

[32] ASTM "ASTM D7369 - 09 Standard Test Method for Determining the Resilient Modulus of Bituminous Mixtures by Indirect Tension Test", ASTM International, West Conshohocken, PA, USA, 2009. https://doi.org/10.1520/D7369-09

[33] Solaimanian, M., Bonaquist, R. F., Tandon, V. "Improved Conditioning and Testing Procedures for HMA Moisture Susceptibility", The National Academies Press, Washington, DC, USA, Rep. NCHRP 589, 2007 https://doi.org/10.17226/23153

[34] Hamedi, G. H., Azarhoosh, A. R., Khodadadi, M. "Effects of Asphalt Binder Modifying with Polypropylene on Moisture Susceptibility of Asphalt Mixtures with Thermodynamically Concepts", Periodica Polytechnica Civil Engineering, 62(4), pp. 901-910, 2018. https://doi.org/10.3311/PPci.11570

[35] Arabani, M., Babamohammadi, S., Azarhoosh, A. R. "Experimental investigation of seashells used as filler in hot mix asphalt", International Journal of Pavement Engineering, 16(6), pp. 502$509,2015$. https://doi.org/10.1080/10298436.2014.943132

[36] Little, D. N., Epps, J. A., Sebaaly, P. E. "The Benefits of Hydrated Lime in Hot Mix Asphalt", [pdf] National Lime Association, Arlington, VI, USA, 2006. Available at: https://www.lime. org/documents/publications/free_downloads/benefits-hydrated-lime2006.pdf 